\title{
Assessment of LV Function in Children with Wilson's Disease: Speckle Tracking Imaging Study
}

\author{
Mahmoud Kamel Ahmed, Mohamed Yahia, Rehab Yaseen, Morad Beshay \\ Department of Cardiology, Menoufia University, Menoufia, Egypt \\ Email:mahmoudkamel35@gmail.com,mahmoud.gabr@med.menofia.edu.eg,m_yahia2000@yahoo.com, \\ dr_r.yaseen@hotmail.com,morad.mena@yahoo.com
}

How to cite this paper: Ahmed, M.K., Yahia M., Yaseen, R. and Beshay, M. (2019) Assessment of LV Function in Children with Wilson's Disease: Speckle Tracking Imaging Study. World Journal of Cardiovascular Diseases, 9, 202-211.

https://doi.org/10.4236/wjcd.2019.93018

Received: February 18, 2019

Accepted: March 19, 2019

Published: March 22, 2019

Copyright (๑) 2019 by author(s) and Scientific Research Publishing Inc. This work is licensed under the Creative Commons Attribution International License (CC BY 4.0).

http://creativecommons.org/licenses/by/4.0/

\begin{abstract}
Background and Objective: Wilson's disease is a genetic disorder of copper metabolism that affects liver and other organs including heart. In early stages of myocardial affection, the left ventricle (LV) appears apparently normal when evaluated by traditional two-dimensional (2D) echocardiography. The aim of this study was to detect subclinical LV dysfunction in children with Wilson's disease using 2D speckle tracking echocardiography. Patients and Methods. Twenty children with Wilson's disease were compared with ageand sex-matched 20 healthy children. All subjects were evaluated by traditional 2D echocardiography and speckle tracking echocardiography. Results. There were no significant differences between patients and controls regarding conventional echo parameters except for lower E mitral flow and E' annular septal peak velocity in patient group. The regional peak longitudinal strain of apical 4 chamber view was $-17.8 \% \pm 4.2 \%$ in patients and $-20.1 \% \pm 2.3 \%$ in control subjects $(\mathrm{P}=0.043)$, and for apical 2 chambers view, it was $-20.1 \% \pm$ $3.6 \%$ in patients and $-22.6 \% \pm 3.4 \%$ in control subjects $(\mathrm{P}=0.034)$ and it was $-18 \% \pm 3.5 \%$ in patients and $-20.5 \% \pm 3.2 \%$ in control subjects $(\mathrm{P}=0.025)$ in apical long axis view. The global peak longitudinal strain was also lower in patients than control group $(18.3 \% \pm 3.2 \%$, and $20.85 \% \pm 2.4 \%)$ respectively $(\mathrm{P}=0.014)$. There were no significant differences between both groups regarding circumferential and radial strains $(\mathrm{P}>0.05)$. Conclusions: Despite apparently normal LV systolic function, the children with Wilson's disease demonstrated significantly lower peak longitudinal strain as an indicator for early affection of LV systolic function.
\end{abstract}

\section{Keywords}

Wilson's Disease, Speckle Tracking Echocardiography 


\section{Introduction}

Wilson's disease is an inherited metabolic disease, in which there is inability of the liver to excrete copper in the bile. As a result, there is excessive copper storage in the liver which usually extends to other organs, practically the brain [1] [2]. Copper deposition may extend to the myocardium, resulting in electrocardiographic changes, arrhythmias, autonomic dysfunction, heart failure and sudden cardiac death [3] [4] [5]. The aim of this study was to detect subclinical LV dysfunction in children with Wilson's disease using two-dimensional speckle tracking strain echocardiography.

\section{Methods}

\subsection{Study Population}

This case-control study included 20 children with Wilson's disease who were recruited from national liver institute in the period between February 2018 and October 2018. Wilson's disease was diagnosed by pediatric hepatologist, depending on the presence of jaundice, Kayser Fleischer ring, liver disease (cirrhotic changes), increased blood levels of copper and decreased blood levels of ceruloplasmin. The diagnosis was confirmed by presence of histological associated features in liver biopsy. Patients with poor quality echocardiographic images, diabetes mellitus, congenital heart disease, primary cardiac valve disease and atrial fibrillation were excluded.

A twenty age and sex matched healthy children were taken as a control group. The study was approved by the local ethical committee of Menoufia University. Cardiac evaluation was done at cardiology department in Menoufia university hospital.

\subsection{Methods}

All the study population subjected to full history taking, clinical examination, standard 12 leads ECG.

\subsection{Conventional Echocardiography}

Echocardiographic examination was done to all participants by using the commercially available (Vivid 9, General Electric Healthcare, GE Vingmed, Norway) equipped with a 1.7 - $4 \mathrm{MHz}$ phased-array transducer. echocardiographic imaging was obtained in the parasternal long- and short-axis, and apical two, three and four-chamber views using standard transducer positions.

LV end-diastolic and end-systolic diameters and volumes, septal and posterior wall thickness, ejection fraction and left atrial diameter were measured in accordance with the recommendations of the American Society of Echocardiography [6] [7].

Pulsed and continuous-wave Doppler was used for valvular assessment. Peak early (E) and late (A) trans-mitral filling velocities were measured from mitral flow.

Doppler Tissue imaging of the septal mitral annulus was obtained from the apical 4-chamber view. Early diastolic wave velocity (E') and the ratio of early 
diastolic mitral flow peak velocity to early diastolic septal annular peak velocity was measured (E/E').

LV Deformation: three cycles from apical views: 4, 2 and 3 chamber views were taken and another three cycles from the short axis view at the level of the LV papillary muscles for measuring circumferential and radial strain.

Frame rate was selected between $40-90$ or at least $40 \%$ of HR. Then after activation of automated function imaging (AFI), digital data were transferred for off-line analysis, using Vivid Nine System Echo Pac, GE Vingmed, Horton, Norway.

\subsection{Statistical Analysis}

Data were analyzed using SPSS software version 20.0. Quantitative data expressed as mean and standard deviation Chi-square test student test, Mann whiney $\mathrm{U}$ test, Kruskal Walls test were used. The $\mathrm{P}$ value $<0.05$ was considered significant.

\section{Results}

Twenty children with Wilson disease (mean age $10.3 \pm 2.6$ years) and 20 age and sex matched healthy controls (mean age $10.6 \pm 2.5$ years) were enrolled in this study (Table 1).

\subsection{Conventional Echocardiography}

There were no significant differences between the studied groups as regard to LA diameter, LVEDD, LVESD and EF (P values $>0.05$ ).

Trans-mitral E velocities were significantly lower in patients compared to controls $(85.5 \pm 18.1 \mathrm{~cm} / \mathrm{s}$ versus $91.7 \pm 22.6 \mathrm{~cm} / \mathrm{s}, \mathrm{P}<0.001)$. Moreover, the septal peak early diastolic velocities (E') were significantly lower in patients compared to controls $(11.2 \pm 2 \mathrm{~cm} / \mathrm{s}$ versus $13.7 \pm 1.8 \mathrm{~cm} / \mathrm{s}, \mathrm{P}<0.001)$. But there was no significant difference between the studied groups as regard $\mathrm{E} / \mathrm{E}$ ' $(\mathrm{P}$ value $>0.05$ ) (Table 2).

\subsection{Speckle-Tracking Echocardiography}

\subsubsection{Segmental, Regional and Global Longitudinal LV Strain}

Segmental analysis showed that peak systolic longitudinal strain values of most segments were statistically significantly lower in patients compared to controls $(\mathrm{P}<0.05)$.

The regional peak longitudinal strain in patient group was lower in all apical views, in apical 4 chamber view it was $-17.8 \% \pm 4.2 \%$ in patients and $-20.1 \% \pm$ $2.3 \%$ in control subjects $(\mathrm{P}=0.045)$, and for apical 2 chambers view it was $-20.1 \% \pm 3.6 \%$ in patients and $-22.6 \% \pm 3.4 \%$ in control subjects $(\mathrm{P}=0.034)$ and it was $-18 \% \pm 3.5 \%$ in patients and $-20.5 \% \pm 3.2 \%$ in control subjects $(\mathrm{P}=$ $0.025)$ in apical long axis view. The global peak longitudinal strain was also lower in patients than control group $(18.3 \% \pm 3.2 \%$, and $20.85 \% \pm 2.4 \%)$ respectively $(\mathrm{p}=0.014)($ Table 3 , Figure 1$)$. 
Table 1. Characteristics of the two studied groups.

\begin{tabular}{ccccc}
\hline & $\begin{array}{c}\text { Control } \\
(\mathbf{n}=20)\end{array}$ & $\begin{array}{c}\text { Wilson } \\
(\mathbf{n}=20)\end{array}$ & Test of Sig. & P \\
\hline Sex (male), n., \% & $13(65 \%)$ & $12(60 \%)$ & $\chi^{2}=0.107$ & 1.000 \\
Age (Y.), mean \pm SD & $10.6 \pm 2.5$ & $10.3 \pm 2.6$ & $\mathrm{t}=0.374$ & 0.711 \\
BSA $\left(\mathrm{m}^{2}\right)$, mean \pm SD & $1.7 \pm 0.2$ & $1.7 \pm 0.2$ & $\mathrm{t}=0.129$ & 0.898 \\
\hline
\end{tabular}

BSA: body surface area.

Table 2. Comparison between the two studied groups according to two dimensional, doppler and tissue doppler echocardiographic parameters.

\begin{tabular}{ccccc}
\hline & $\begin{array}{c}\text { Control } \\
(\mathbf{n}=20)\end{array}$ & $\begin{array}{c}\text { Wilson } \\
(\mathbf{n}=20)\end{array}$ & Test of Sig. & $\mathbf{P}$ \\
\hline IVSD $(\mathrm{cm})$ & $0.7 \pm 0.1$ & $0.8 \pm 0.2$ & $\mathrm{t}=1.707$ & 0.096 \\
LVPW $(\mathrm{cm})$ & $0.7 \pm 0.1$ & $0.8 \pm 0.2$ & $\mathrm{t}=0.675$ & 0.504 \\
LVEDD $(\mathrm{cm})$ & $4.8 \pm 0.5$ & $4.7 \pm 0.6$ & $\mathrm{t}=0.279$ & 0.782 \\
LVESD (cm) & $3 \pm 0.5$ & $3 \pm 0.4$ & $\mathrm{t}=0.229$ & 0.820 \\
LVEDV (ml) & $109.5 \pm 22.9$ & $105.1 \pm 32.5$ & $\mathrm{t}=0.495$ & 0.623 \\
LVESV (ml) & $38.2 \pm 14.3$ & $35.9 \pm 13.1$ & $\mathrm{U}=181$ & 0.620 \\
LVEF $(\%)$ & $65 \pm 6.4$ & $64.7 \pm 4.1$ & $\mathrm{t}=0.258$ & 0.797 \\
LA (cm) & $3.2 \pm 0.4$ & $3.3 \pm 0.6$ & $\mathrm{t}=0.453$ & 0.653 \\
E $(\mathrm{cm} / \mathrm{s})$ & $91.7 \pm 22.6$ & $85.5 \pm 18.1$ & $\mathrm{t}=4.120$ & $<0.001^{*}$ \\
A (cm/s) & $59.6 \pm 11.8$ & $60.9 \pm 11.8$ & $\mathrm{t}=0.366$ & 0.739 \\
E/A ratio & $1.6 \pm 0.4$ & $1.4 \pm 0.4$ & $\mathrm{U}=173$ & 0.478 \\
e' (cm/s) & $13.7 \pm 1.8$ & $11.2 \pm 2$ & $\mathrm{t}=4.120$ & $<0.00^{*}$ \\
A' (cm/s) & $7.6 \pm 1.5$ & $8 \pm 2$ & $\mathrm{t}=0.728$ & 0.471 \\
E/e' & $6.7 \pm 1.6$ & $7.8 \pm 2$ & $\mathrm{t}=1.907$ & 0.064 \\
\hline
\end{tabular}

IVSD: interventricular septal thickness at end diastole, LVPW: left ventricular posterior wall thickness, LVEDD: left ventricular end diastolic dimension, LVESD: left ventricular end systolic dimension, LVEDV: left ventricular end diastolic volume, LVESV: left ventricular end systolic volume, LVEF: left ventricular ejection fraction. LA: left atrium, E: early peak pulsed doppler velocity on mitral valve, A: late pulsed doppler velocity on mitral valve, e': early tissue velocity of septal annulus. t: Student t-test $U$ : Mann Whitney test, $\mathrm{p}$ : $\mathrm{p}$ value for comparing between the studied groups. All variables are expressed by mean \pm standard deviation. *: Statistically significant at $\mathrm{P} \leq 0.05$.

\subsubsection{Circumferential and Radial Strain of LV}

There was no significant difference between the studied groups regarding circumferential LV strain $(-16.7 \% \pm 4.5 \%$ versus $-19.3 \% \pm 5 \% \mathrm{P}>0.05)$.

Also, there was no significant difference between the studied groups regarding radial strain of LV $(38.5 \% \pm 16 \%$ versus $40.3 \% \pm 15.2 \% \mathrm{P}>0.05)$ (Table 4 , Figure 2).

\section{Discussion}

Copper deposition inside the myocardium in Wilson's disease will affect LV function. The copper induced cardiomyopathy in Wilson's disease is related to 
Table 3. Longitudinal strain values of the two studied groups.

\begin{tabular}{|c|c|c|c|c|}
\hline & $\begin{array}{l}\text { Control } \\
(n=20)\end{array}$ & $\begin{array}{l}\text { Wilson } \\
(\mathrm{n}=20)\end{array}$ & Test of Sig. & $\mathbf{P}$ \\
\hline Basal septal & $-19.8 \pm 2$ & $-17.7 \pm 3.2$ & $\mathrm{t}=2.389$ & $0.02^{\star}$ \\
\hline Mid septal & $-21.4 \pm 2.9$ & $-19.1 \pm 3.6$ & $\mathrm{t}=2.094$ & $0.043^{*}$ \\
\hline Apical septal & $-23.2 \pm 4.4$ & $-20.2 \pm 5.5$ & $\mathrm{t}=1.877$ & 0.07 \\
\hline Apical lateral & $-20.2 \pm 5.7$ & $-17.1 \pm 5.3$ & $\mathrm{t}=1.759$ & 0.08 \\
\hline Mid lateral & $-19.4 \pm 3$ & $-16 \pm 6.3$ & $\mathrm{t}=2.118$ & $0.04^{*}$ \\
\hline Basal lateral & $-20.4 \pm 3$ & $-17.1 \pm 5.5$ & $\mathrm{t}=2.251$ & $0.03^{\star}$ \\
\hline Basal inferior & $-22.3 \pm 2.3$ & $-19.4 \pm 5.5$ & $\mathrm{t}=2.180$ & $0.039^{*}$ \\
\hline Mid inferior & $-22.3 \pm 2.3$ & $-20.2 \pm 4.7$ & $\mathrm{t}=1.810$ & 0.078 \\
\hline Apical inferior & $-25.1 \pm 5.1$ & $-22.8 \pm 4.4$ & $\mathrm{t}=1.497$ & 0.143 \\
\hline Apical anterior & $-22.4 \pm 7.4$ & $-16.3 \pm 7.2$ & $\mathrm{U}=104$ & $0.009^{*}$ \\
\hline Mid anterior & $-20.5 \pm 7.1$ & $-17.1 \pm 5.8$ & $t=1.663$ & 0.104 \\
\hline Basal anterior & $-23.2 \pm 5$ & $-22.4 \pm 6.6$ & $\mathrm{t}=0.459$ & 0.649 \\
\hline Basal posterior & $-18 \pm 3.8$ & $-17.7 \pm 4.3$ & $\mathrm{t}=0.225$ & 0.823 \\
\hline Mid posterior & $-18.3 \pm 2.9$ & $-17.7 \pm 4.5$ & $t=0.502$ & 0.618 \\
\hline Apical posterior & $-22.1 \pm 2.9$ & $-18.8 \pm 5.4$ & $\mathrm{t}=2.371$ & $0.025^{*}$ \\
\hline Apical anteroseptal & $-24 \pm 4.2$ & $-17 \pm 6.2$ & $t=4.168$ & $<0.001^{*}$ \\
\hline Mid anteroseptal & $-21.1 \pm 6.2$ & $-16.2 \pm 6.9$ & $\mathrm{U}=105$ & $0.009^{*}$ \\
\hline Basal anteroseptal & $-19.4 \pm 6.6$ & $-18 \pm 6$ & $\mathrm{U}=174$ & 0.495 \\
\hline GLPS_A4C (\%) & $-20.1 \pm 2.3$ & $-17.8 \pm 4.2$ & $t=2.093$ & $0.043^{*}$ \\
\hline GLPS_A2C (\%) & $-22.6 \pm 3.4$ & $-20.1 \pm 3.6$ & $\mathrm{t}=2.193$ & $0.034^{*}$ \\
\hline GLPS_LAX (\%) & $-20.5 \pm 3.2$ & $-18 \pm 3.5$ & $\mathrm{t}=2.340$ & $0.025^{*}$ \\
\hline GLPS_Avg (\%) & $-20.85 \pm 2.4$ & $-18.3 \pm 3.2$ & $t=2.578$ & $0.014^{*}$ \\
\hline
\end{tabular}

GLPS_A4C: apical 4 chamberglobal longitudinal peak systolic strain, GLPS_A2C: apical 2 chamber global longitudinal peak systolic strain, GLPS_LAX: apical long axisglobal longitudinal peak systolic strain, GLPS_Avg: average global longitudinal peak systolic strain. t: Student t-test $U$ : Mann Whitney test, p: $p$ value for comparing between the studied groups. All variables are expressed by mean \pm standard deviation. *: Statistically significant at $\mathrm{P} \leq 0.05$.

various mechanisms; first, it is caused by intra- and extracellular pathological accumulations of copper that lead to infiltrative myocardial diseases [8] [9]. Second, copper ions had toxic effects which may result in damage of myocytes. Copper stimulates the production of interleukin- 6 and interleukin- $1 \beta$ with resultant oxidative stress [10] [11]. Furthermore, Patients with Wilson's disease demonstrated a polymorphism in the gene which encoded an interleukon-1 receptor antagonist [12] [13]. Finally, copper activated sphingomyelin, which activates cardiac apoptosis [14].

In our study, all patients had Wilson's disease with hepatic manifestations, and no one had neurologic manifestations. Severe cardiac affection was observed in patients with neurogenic Wilson's disease than patients with hepatic Wilson's 


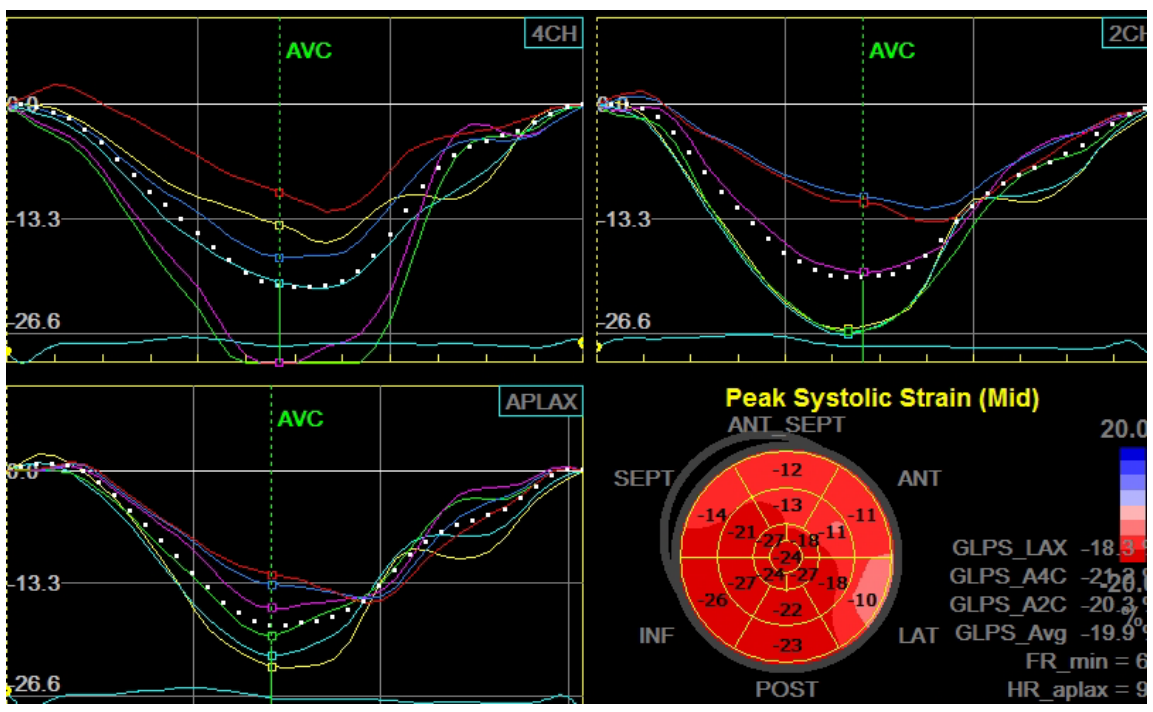

Figure 1. Peak longitudinal strain of all apical view in one of the affected children with Wilson disease.

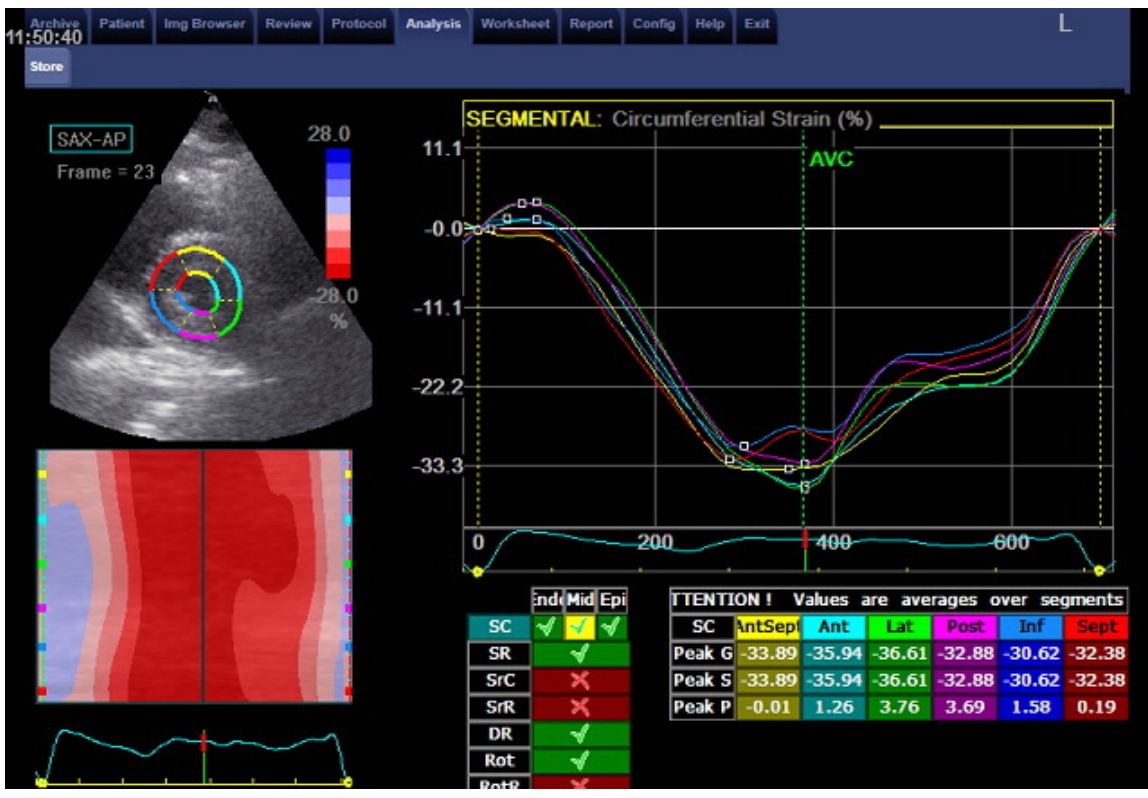

Figure 2. Normal circumferential strain of one of control group.

Table 4. Comparison between the two studied groups according to different parameters.

\begin{tabular}{ccccc}
\hline & $\begin{array}{c}\text { Control } \\
(\mathbf{n}=20)\end{array}$ & $\begin{array}{c}\text { Wilson } \\
(\mathbf{n}=20)\end{array}$ & Test of Sig. & $\mathbf{P}$ \\
\hline Circumferential Strain & $-19.3 \pm 5$ & $-16.7 \pm 4.5$ & $\mathrm{t}=1.743$ & 0.089 \\
Radial Strain & $40.3 \pm 15.2$ & $38.5 \pm 16$ & $\mathrm{t}=0.369$ & 0.714 \\
\hline
\end{tabular}

Variables are expressed by mean \pm standard deviation: Student $t$-test $p$ : $p$ value for comparing between the studied groups.

disease [15]. Copper accumulation may be undetected for a longer time in patients with neurogenic manifestations, while symptoms of hepatic affections ap- 
pear at the earlier stage of the disease [16].

In early stages of the Wilson's disease, the LV appears apparently normal when evaluated by traditional 2D echocardiographic parameters. Early detection of LV dysfunction by the relatively new echocardiographic technique; speckle tracking echocardiographic, helps in strict control of blood copper levels to prevent development of cardiomyopathy. The current study evaluated LV function by speckle tracking echocardiography in 20 children with Wilson's disease, and compared the results to 20 age and sex matched healthy children. The mean LV ejection fraction did not differ significantly in patients and controls. Trans-mitral E velocities and the septal peak early diastolic velocities (E') were significantly lower in patients in comparison to control participants, which reflects impaired LV filling in patients with Wilson's disease.

Our results agreed with Malgorzata et al. who evaluated LV function in 125 adult patients with Wilson's disease and reported non-significant differences in LV ejection fractions in comparison to controls, while diastolic dysfunction was only present in patients presented with neurological form rather than hepatic form. They also reported mitral valve disease in some patients with Wilsons disease, in contrast, our study reported no valvular pathology [17].

Similarly, Elkiran et al. studied 22 children with Wilson's disease, and they reported diastolic dysfunction [18]. In another study, the LV systolic function measured by ejection fraction did not differ significantly between Wilson's disease and controls, however, diastolic dysfunction was more frequent in patients with Wilson's disease [19].

Hlubocka $\mathrm{Z}$ et al. compared 2D echocardiographic data of 42 patients with Wilson's disease to 42 healthy subjects. They reported a non-significant trend towards lower LV ejection fraction values in patients with Wilson's disease (62\% versus $64 \%$ ), the LV diastolic function did not differ in the two groups [20].

In a recent study by Quick et al., 61 patients with Wilson's disease were evaluated by cardiac magnetic resonance. They reported no differences between patients and controls with respect to LV ejection fractions, however, there were significant differences between the two groups with respect to late gadolinium enhancement. Regarding such data, they suggested that patients with Wilson's disease are at risk of developing impaired LV functions [21].

Fewer studies concerned with evaluation of children with Wilson's disease by speckle tracking echocardiography. Speckle tracking echocardiography provides advantages over tissue doppler echocardiography in the assessment of regional LV function as it is not affected by stretching of the nearby myocardial segments and it is not angle dependence [22]. In the current study, the average longitudinal peak systolic strains were significantly lower in diseased children in comparison to control participants, while, the circumferential and radial strains did not significantly differ between the 2 groups. These finding agreed with a study which was carried by Karakurt et al., who reported significant differences between children with Wilson's disease and control participants with respect to diastolic dysfunction, regional myocardial deformations, rotational strain and 
strain rate $[23]$.

\section{Conclusion}

Despite apparently normal LV systolic function, the patients with Wilson's disease demonstrated a significant reduction in regional and global LV longitudinal strain as an indicator of early affection of LV systolic function.

\section{Limitations}

The study was based on a small number of patients as Wilson's disease is being a rare; therefore, the results need to be verified using a larger sample size. Another limitation is lack of neurological form of the disease, as our patients were recruited from a liver tertiary center. In addition, there was a difficulty to assess the drug therapy of Wilson's disease on myocardial pathology.

\section{Conflicts of Interest}

The authors declare no conflicts of interest regarding the publication of this paper.

\section{References}

[1] Rosencrantz, R. and Schilsky, M. (2011) Wilson's Disease: Pathogenesis and Clinical Considerations in Diagnosis and Treatment. Seminars in Liver Disease, 31, 245-259. https://doi.org/10.1055/s-0031-1286056

[2] Bennett, J. and Hahn, S.H. (2011) Clinical Molecular Diagnosis of Wilson's Disease. Seminars in Liver Disease, 13, 233-238. https://doi.org/10.1055/s-0031-1286054

[3] Aggarwal, A. and Bhatt, M. (2013) Update on Wilson Disease. International Review of Neurobiology, 110, 313-348. https://doi.org/10.1016/B978-0-12-410502-7.00014-4

[4] Kuan, P. (1987) Cardiac Wilson's Disease. Chest, 91, 579-583. https://doi.org/10.1378/chest.91.4.579

[5] Meenakshi-Sundaram, S., Sinha, S., Rao, M., Prashanth, L.K., Arunodaya, G.R., Rao, S., et al. (2004) Cardiac Involvement in Wilson's Disease-An Electrocardiographic Observation. The Journal of the Association of Physicians of India, 52, 294-296.

[6] Lang, R.M., Badano, L.P., Mor-Avi, V., Afilalo, J., Armstrong, A., et al. (2015) Recommendations for Cardiac Chamber Quantification by Echocardiography in Adults: An Update from the American Society of Echocardiography and the European Association of Cardiovascular Imaging. Journal of the American Society of Echocardiography, 28, 1-39. https://doi.org/10.1016/j.echo.2014.10.003

[7] Nagueh, S.F., Smiseth, O.A., Appleton, C.P., Byrd, B.F., Dokainish, H., et al. (2016) Recommendations for the Evaluation of Left Ventricular Diastolic Function by Echocardiography: An Update from the American Society of Echocardiography and the European Association of Cardiovascular Imaging. European Heart Journal-Cardiovascular Imaging, 17, 1321-1360. https://doi.org/10.1093/ehjci/jew082

[8] Moinuddin, M.J., Figueredo, V. and Amanullah, A.M. (2010) Infiltrative Diseases of the Heart. Reviews in Cardiovascular Medicine, 11, 218-227.

[9] Maron, B.J., Towbin, J.A., Thiene, G., et al. (2006) Contemporary Definitions and 
Classification of the Cardiomyopathies: An American Heart Association Scientific Statement from the Council on Clinical Cardiology, Heart Failure and Transplantation Committee; Quality of Care and Outcomes Research and Functional Genomics and Translational Biology Interdisciplinary Working Groups; and Council on Epidemiology and Prevention. Circulation, 113, 1807-1816.

https://doi.org/10.1161/CIRCULATIONAHA.106.174287

[10] Ansteinsson, V., Refsnes, M., Skomedal, T., Osnes, J.B., Schiander, I. and Lag, M. (2009) Zinc- and Copper-Induced Interleukin-6 Release in Primary Cell Cultures from Rat Heart. Cardiovascular Toxicology, 9, 86-94.

https://doi.org/10.1007/s12012-009-9043-5

[11] Bruha, R., Vitek, L., Marecek, Z., et al. (2012) Decreased Serum Antioxidant Capacity in Patients with Wilson Disease Is Associated with Neurological Symptoms. Journal of Inherited Metabolic Disease, 35, 541-548. https://doi.org/10.1007/s10545-011-9422-5

[12] Gromadzka, G. and Czlonkowska, A. (2011) Influence of IL-1RN Intron 2 Variable Number of Tandem Repeats (VNTR) Polymorphism on the Age at Onset of Neuropsychiatric Symptoms in Wilson's Disease. International Journal of Neuroscience, 121, 8-15. https://doi.org/10.3109/00207454.2010.523131

[13] Gromadzka, G., Kruszynska, M., Wierzbicka, D., et al. (2015) Gene Variants Encoding Proteins Involved in Antioxidant Defense System and the Clinical Expression of Wilson Disease. Liver International, 35, 215-222. https://doi.org/10.1111/liv.12493

[14] Lang, P.A., Schenck, M., Nicolay, J.P., et al. (2007) Liver Cell Death and Anemia in Wilson Disease Involve Acid Sphingomyelinase and Ceramide. Nature Medicine, 13, 164-170. https://doi.org/10.1038/nm1539

[15] Cheng, N., Wang, H., Dong, J., et al. (2015) Elevated Serum Brain Natriuretic Peptide and Matrix Metalloproteinases 2 and 9 in Wilson's Disease. Metabolic Brain Disease, 30, 1087-1091. https://doi.org/10.1007/s11011-015-9685-x

[16] Ferenci, P., Czlonkowska, A., Merle, U., et al. (2007) Late-Onset Wilson's Disease. Gastroenterology, 132, 1294-1298. https://doi.org/10.1053/j.gastro.2007.02.057

[17] Buksińska-Lisik, M., Litwin, T., Pasierski, T. and Członkowska, A. (2017) Cardiac Assessment in Wilson's Disease Patients Based on Electrocardiography and Echocardiography Examination. Archives of Medical Science. https://doi.org/10.5114/aoms.2017.69728

[18] Elkiran, O., Karakurt, C., Selimoglu, A., et al. (2013) Subclinical Diastolic Dysfunction in Children with Wilson's Disease Assessed by Tissue Doppler Echocardiography: A Possible Early Predictor of Cardiac Involvement. Acta Cardiologica, 68, 181-187. https://doi.org/10.1080/AC.68.2.2967276

[19] Quick, S., Reuner, U., Weidauer, M., Hempel, C., Heidrich, F.M., Mues, C., Sveric, K.M., et al. (2019) Cardiac and Autonomic Function in Patients with Wilson's Disease. Orphanet Journal of Rare Diseases, 14, 22. https://doi.org/10.1186/s13023-019-1007-7

[20] Hlubocká, Z., Marecek, Z., Linhart, A., Kejková, E., Pospísilová, L., Martásek, P. and Aschermann, M. (2002) Cardiac Involvement in Wilson Disease. Journal of Inherited Metabolic Disease, 25, 269-277. https://doi.org/10.1023/A:1016546223327

[21] Quick, S., Weidauer, M., Heidrich, F.M., Sveric, K., Reichmann, H., Ibrahim, K., Strasser, R.H., Linke, A., Speiser, U. and Reuner, U. (2018) Cardiac Manifestation of Wilson's Disease. Journal of the American College of Cardiology, 72, 2808-2809. https://doi.org/10.1016/j.jacc.2018.08.2197 
[22] Forsey, J., Friedberg, M. and Mertens, L. (2013) Speckle Tracking Echocardiography in Pediatric and Congenital Heart Disease. Echocardiography, 30, 447-459. https://doi.org/10.1111/echo.12131

[23] Karakurt, C., Çelik, S., Selimoğlu, A., Varol, I., Karabiber, H. and Yoloğlu, S. (2016) Strain and Strain Rate Echocardiography in Children with Wilson's Disease. Cardiovascular Journal of Africa, 27, 307-314. 